\title{
Análisis morfológico, dietario y molecular de heces recolectadas en la Reserva Geobotánica Pululahua para la identificación del lobo de páramo (Lycalopex culpaeus, Molina 1782).
}

\section{Morphological, dietary and molecular analysis of feces collected in the Pululahua Geobotanic Reserve for andean fox (Lycalopex culpaeus, Molina 1782) identification.}

ESTEFANY JARRÍN-PORRAS, DAYANA SANDOVAL-MOREJÓN, ERIKA LLUMIQUINGA, CRISTINA PAREDES-MACHADO, MAYRA HEREDIA, MARÍA AUGUSTA CHÁVEZ-LARREA, *MARÍA CLAUDIA SEGOVIA-SALCEDO

Carrera de Ingeniería en Biotecnología, Departamento de Ciencias de la Vida y la Agricultura

Universidad de las Fuerzas Armadas ESPE, Av. General Rumiñahui s/n, Sangolquí Ecuador

*mcsegovia@espe.edu.ec, P.O. BOX:171-5-231,+59302.398.9400

\section{RESUMEN}

El estudio de los hábitos alimenticios del lobo de páramo (Lycalopex culpaeus) es importante para entender su comportamiento y establecer medidas de conservación y manejo de esta especie, especialmente cuando comparte territorio con asentamientos humanos. Estudios a partir del análisis de heces fecales de fauna silvestre permiten un acercamiento no invasivo a los hábitos alimenticios del animal. El objetivo de esta investigación fue realizar el análisis morfológico y dietario de heces recolectadas en la Reserva Geobotánica Pululahua (RGP) para la identificación del lobo de páramo (L. culpaeus), además de llevar a cabo un análisis molecular complementario para confirmar dicha identificación. Se recolectaron 32 muestras de heces durante agosto de 2015, en la RGP y se realizó un análisis morfológico evaluando contenido, forma y lugar de recogida. En el análisis de la dieta las muestras fecales se disgregaron para recuperar restos de alimentos. Para el análisis molecular se procedió a la extracción de ADN siguiendo el método $2 \mathrm{CTAB} / \mathrm{CAl}$ estandarizado para lobo de páramo, cuyas muestras posteriormente fueron amplificadas por PCR simple utilizando primers del gen cytb (citocromo b) específico para el 
género Lycalopex. Se identificaron plantas de la familia Poceae, con un $26 \%$ del total de la alimentación, mamíferos pequeños (18\%) como roedores del género Microryzomys, Rhipidomys, Reithrrodontomys y Olygorizomys, aves, insectos, plásticos y carroña, siendo la mayoría de los animales parte de la fauna habitual en la RGP. En este estudio se determinó que el lobo de páramo es un organismo oportunista y su dieta varía según las condiciones del hábitat en el que se encuentre, además, no es el principal responsable de la disminución de aves domésticas que habitan en la reserva. De las seis muestras seleccionadas para el análisis molecular, sólo de cuatro muestras se logró extraer ADN con una pureza promedio de 1.78. En el análisis por PCR no se logró amplificar el fragmento cytb del citocromo b para la identificación de lobo de páramo.

Palabras claves: muestras fecales, alimentación del zorro culpeo, extracción ADN, PCR, citocromo b, Ecuador.

\section{ABSTRACT}

The study of the feeding habits of the Andean fox (Lycalopex culpaeus) is important to understand its behavior and establish conservation management measures for this species, especially when it shares territory with human settlements. Studies based on the analysis of feces from wild fauna allow a non-invasive approach to the animal's feeding habits. The objective was to carry out the morphological and dietary analysis of feces collected in the Pululahua Geobotanical Reserve to identify the Andean fox (L. culpaeus), as well as to carrying out a complementary molecular analysis to confirm said identification. During August 2015 in the Pululahua Geobotanical Reserve, Quito, Pichincha (Ecuador) 32 feces were collected. A morphological analysis of the faeces was carried out, taking into account for evaluation parameters like: sample content, form and place of collection. In the diet analysis, the faecal samples were disaggregated to recover food remains. For molecular analysis, DNA extraction was carried out following the standardized 2CTAB / CAI method for Andean fox, which were subsequently amplified by simple PCR using primers of the cytb (cytochrome b) gene specific for the genus Lycalopex. Plants of Poceae family were identified, with $26 \%$ of the total diet. Also, there were identified small mammals (18\%) as rodents of the genus Microryzomys, Rhipidomys, Reithrrodontomys and Olygorizomys, birds, insects, plastics and carrion, being the majority of these animals part of the habitual fauna in the RGP. This study allowed to determine that the Andean fox is an opportunistic organism and its diet varies according to the conditions of the habitat in which it is found. On the other hand, the Andean fox is not the main responsible for the poultry decrease that inhabit the reserve. The DNA extration was posible only in four samples than the six was selected with an average purity of 1.78. In the PCR analysis, the cytochrome b cytotography fragment cannot be amplified for the identification of $L$. culpaeus.

Key words: fecal samples, feeding of the Andean fox, DNA extraction, PCR, cytochrome b, Ecuador.

\section{INTRODUCCIÓN}

El Ecuador cuenta con una superficie total de $283560 \mathrm{~km} 2$, de los cuales, alrededor del $98 \%$ corresponde al área continental. A pesar de ser un espacio reducido, es considerado uno de los 17 países más mega diversos del mundo (Ministerio del ambiente del Ecuador, 2010). Además, tiene un 33,26\% de su ecosistema bajo protección o cuidado ambiental, destacándose como el segundo país con mayor área protegida en Latino América (Ministerio del ambiente y agua, 2016), (Cedeño, 2016). Existen parques nacionales, refugios silvestres, áreas nacionales y reservas que se dedican a la conservación y correcto 
manejo de la biota interna de cada una de ellas. No obstante, la información sobre especies silvestres existente es escasa, como en el caso del lobo de páramo.

El lobo de páramo es uno de los cánidos silvestres más grandes del país, puede llegar a pesar entre 6 a $13 \mathrm{~kg}$, y medir hasta 1,70 m de largo (Veintimilla, 2015); se distribuye a lo largo de la cordillera de los Andes, desde Colombia hasta Chile (Zapata, Travaini, Delibes, \& Martínez-Peck, 2005). También conocido como zorro culpeo, zorro colorado o zorro andino, puede habitar en terrenos áridos y semiáridos, aunque también se ubica en hábitats con abundante vegetación (Canevari \& Vaccaro, 2007; Castellanos, Vallejo, \& Moscoso, 2020). Dentro del Ecuador se distribuye en las zonas templadas y alto andinas entre $1800 \mathrm{~m}$ y $4000 \mathrm{~m}$ de altitud (Trujillo \& Trujillo, 2007). Por su distribución, la alimentación del lobo de páramo se basa principalmente en roedores, conejos, aves, insectos y plantas (Guzmán-Sandoval, Sielfeld, \& Ferrú, 2007). Adicionalmente, se ha reportado que tiene hábitos alimentarios oportunistas, alimentándose de las presas que están a su disposición (Veintimilla, 2015), dándole una mala fama de depredador.

La RGP se encuentra dentro de la distribución del lobo del páramo y, es la única en su categoría en el país, dado a su particular geología e historia vulcanológica. Está formada por el cráter del volcán inactivo Pululahua, en cuyo interior se destacan tres elevaciones: el Pondoña, el Chivo y el Pan de azúcar. La reserva se ubica al noroccidente de la Parroquia de San Antonio de Pichincha, a $40 \mathrm{~km}$ del Distrito Metropolitano de Quito, cerca de la Mitad del Mundo (J. Vallejo, 2015). En el interior de la reserva se encuentra una caldera volcánica habitada por la comunidad San Isidro. La comunidad subsiste de la ganadería y agricultura, tiene animales domésticos como gallinas, perros, vacas y cerdos. Al ser la única comunidad que habita la reserva, no tiene un control sobre sus animales, por lo que las gallinas han ido desapareciendo paulatinamente. Los habitantes de la comunidad culpan al lobo de páramo de estas desapariciones y desean cazarlo. El conflicto mencionado anteriormente, puede ocasionar que el lobo de páramo pase de ser un animal categorizado de menor preocupación (Noguera-Urbano, Ramírez-Chaves, \& Torres-Martínez, 2016) a estar categorizado como animal en peligro de extinción si no se llega a controlar el problema

Es así que, el objetivo del presente estudio es determinar la dieta del lobo de páramo mediante un análisis morfológico de las heces del animal y adicionalmente aprovechar el material biológico para confirmar que los datos corresponden a este cánido silvestre y no a perros ferales que se encuentren en la misma zona. Para ello se utilizará la técnica molecular PCR, mediante la amplificación del fragmento cytb del citocromo b.

\section{MATERIALES Y MÉTODOS}

\section{Recolección de las muestras fecales}

El estudio se realizó en el centro norte de la provincia de Pichincha, a 25 kilómetros al norte de Quito, en Ecuador $\left(0^{\circ} 02^{\prime} 17^{\prime \prime} \mathrm{N}, 78^{\circ}\right.$ $27^{\prime} 47^{\prime \prime}$ O), específicamente en las áreas protegidas de la Reserva Geobotánica Pululahua situada a 2250 metros sobre el nivel del mar.

Se recolectaron 32 muestras de heces de lobo de páramo durante los meses de agosto y septiembre de 2015. Las heces fecales fueron tomadas con guantes de nitrilo, depositadas en fundas plásticas herméticas y etiquetadas con la siguiente información: código, categoría, fecha, lugar de muestreo y coordenadas geográficas (GPS map 76), según el protocolo de Quinga et al. (2012). Las muestras fueron colocadas en una nevera portátil hasta el transporte al sitio de almacenamiento definitivo. 
Análisis morfológico, dietario y molecular de heces recolectadas en la Reserva Geobotánica Pululahua para la identificación del lobo de páramo.

Estefany Jarrín-Porras, Dayana Sandoval-Morejón, Erika Llumiquinga, Cristina Paredes-Machado, Mayra Heredia, María Augusta Chávez-Larrea, María Claudia Segovia-Salcedo - VÍNCULOS-ESPE (2020) VOL.5, No.3: 33 - 49

\section{Almacenamiento de las heces fecales}

Las muestras de heces fecales fueron almacenadas en el laboratorio de Biotecnología Animal de la Universidad de las Fuerzas Armadas ESPE, de acuerdo a la categoría (frescas, semifrescas y secas) a la que pertenecían. Se almacenaron las muestras secas a temperatura ambiente $\left(25^{\circ} \mathrm{C}\right)$ en cajas Petri para el análisis dietario del lobo del páramo. A partir de las muestras semifrescas se tomaron 4 gramos de heces fecales y se almacenaron a $-20^{\circ} \mathrm{C}$ en fundas herméticas para los subsecuentes análisis moleculares.

\section{Análisis morfológico de las muestras fecales}

Durante la recolección en campo, se diferenciaron las heces de lobo de páramo de otras especies de animales, como felinos, utilizando claves de identificación basadas en características generales de las heces de carnívoros cordilleranos. Se evaluaron parámetros como forma, contenido y lugar de recolección (Tabla 1).

Tabla 1. Características generales de las heces de acarnívoros de cordillera (Palacios, 2007).

\begin{tabular}{|c|c|c|c|c|}
\hline Especie & Contenido & Forma & Diámetro & Lugar \\
\hline $\begin{array}{l}\text { Gato andino, } \\
\text { gato de } \\
\text { pajonal y gato } \\
\text { doméstico }\end{array}$ & $\begin{array}{l}\text { Pelos, pedazos de huesos } \\
\text { normalmente pequeños, } \\
\text { de roedores, y/o plumas }\end{array}$ & $\begin{array}{l}\text { Heces con } \\
\text { constricciones } \\
\text { cercanas y muy } \\
\text { marcadas, formando } \\
\text { un "rosario" }\end{array}$ & $\begin{array}{l}\text { Los valores medios } \\
\text { rondan los } 18 \mathrm{~mm} \text {, } \\
\text { con completa } \\
\text { superposición de } \\
\text { tamaños entre las dos } \\
\text { especies de gato. }\end{array}$ & $\begin{array}{l}\text { Generalmente en cuevas } \\
\text { pequeñas que acumulan varias } \\
\text { heces, formando letrinas. } \\
\text { También en otros ligares } \\
\text { cubiertos o al aire libre }\end{array}$ \\
\hline Zorros y perros & $\begin{array}{l}\text { Pelos, huesos (pequeños } \\
\text { o intermedios, como de } \\
\text { liebre), plumas, insectos, } \\
\text { escorpiones }\end{array}$ & $\begin{array}{l}\text { Heces con } \\
\text { constricciones } \\
\text { separadas, } \\
\text { característica } \\
\text { terminación en } \\
\text { punta. }\end{array}$ & $\begin{array}{l}\text { Los calores medios } \\
\text { aproximados (pero } \\
\text { con muchas } \\
\text { superposiciones) son } \\
11 \text { mm para el zorro } \\
\text { colorado. }\end{array}$ & $\begin{array}{l}\text { Generalmente al aire libre, no } \\
\text { acumuladas, pero pueden } \\
\text { formar letrinas incluso } \\
\text { combinadas con heces de gato. } \\
\text { También se las encuentra sobre } \\
\text { cáscaras. }\end{array}$ \\
\hline Puma & $\begin{array}{l}\text { Pelos, pedazos de huesos } \\
\text { (de variados tamaños, } \\
\text { incluyendo porciones } \\
\text { grandes como de } \\
\text { camélido), plumas. }\end{array}$ & $\begin{array}{l}\text { Heces "gatunas" con } \\
\text { constricciones } \\
\text { cercanas, formando } \\
\text { un rosario. }\end{array}$ & $\begin{array}{l}\text { Tamaño grande o muy } \\
\text { grande, diámetro } \\
\text { medio } 35 \mathrm{~mm}\end{array}$ & $\begin{array}{l}\text { Cuevas espaciosas o al aire } \\
\text { libre, solas o formando letrinas, } \\
\text { en la base de perderos, cerca de } \\
\text { animales cazados }\end{array}$ \\
\hline Zorrino & $\begin{array}{l}\text { Restos de insectos y } \\
\text { escorpiones, las heces } \\
\text { son frágiles, se } \\
\text { desgranan. }\end{array}$ & $\begin{array}{l}\text { Tamaño pequeño, } \\
\text { fragmentos } \\
\text { separados sin una } \\
\text { forma determinada }\end{array}$ & $\begin{array}{l}\text { El diámetro medio } \\
\text { desde } 9-10 \mathrm{~mm} \text { pero } \\
\text { es muy variable. }\end{array}$ & $\begin{array}{l}\text { Normalmente semienterradas en } \\
\text { cuevas chicas localizadas en la } \\
\text { base de pedreros, puede estar al } \\
\text { aire libre en la boca de la } \\
\text { cueva. }\end{array}$ \\
\hline
\end{tabular}




\section{Análisis dietario del lobo de páramo}

Se emplearon pinzas y guantes de nitrilo para separar residuos animales y vegetales a partir de las heces fecales secas. La identificación de los elementos encontrados en las heces se realizó en colaboración con el Instituto de Ciencias Biológicas de la Escuela Politécnica Nacional, donde se compararon con especímenes de la colección de mamíferos y aves, además, se emplearon textos de referencia, fotografías y notas de campo del sitio de muestreo para caracterizar un elemento particular.

\section{Análisis molecular de las muestras de heces fecales}

Las muestras de heces fecales semifrescas fueron utilizadas para la extracción de ADN genómico mediante el método manual 2 bromuro de cetiltrimetilamonio/cloroformo - alcohol isoamílico (2CTAB/CAI) descrito por Quinga et al., (2012). Se evaluaron los parámetros de concentración (ng/ $\mu \mathrm{L}$ ) y calidad (A 260/280 nm) de las muestras de ADN aislado. Las muestras de ADN fueron empleadas para el análisis de identificación de Lycalopex culpaeus mediante la reacción en cadena de la polimerasa (PCR). Se utilizó heces de lobo (Lycalopex culpaeus) del Zoológico de Cuenca Bioparque Amaru como control positivo y heces de perro (Canis lupus familiaris) como control negativo de reacción. Se utilizaron los primers diseñados por Quinga et al., (2012), específicos para el género Lycalopex con secuencias 5'-TTCCAGCACCATCCAATATTTCCGC-3' y 3'-GGCGCCGTTTGCATGTATGTAACG-5' que amplificaban un fragmento de $200 \mathrm{pb}$ correspondiente al gen citocromo b (Cy+b).

\section{Análisis estadístico}

Se obtuvieron las frecuencias relativas del volumen de muestras fecales recolectadas en diferentes zonas de la RGP. Los elementos dietarios identificados de las muestras fecales secas del lobo de páramo (Lycalopex culpaeus) fueron clasificados en grupos: mamíferos, aves, invertebrados, plantas y otros, para obtener la frecuencia relativa con el software Excel.

\section{Resultados}

\section{Zonas de colección de las muestras}

El área de estudio abarcó ecosistemas variados, de los que un $75 \%$ corresponde a bosque húmedo montano bajo; un $12,5 \%$ a una asociación de bosque húmedo montano bajo con bosque muy húmedo montano, y un 12,5\% a una asociación de bosque seco montano bajo con bosque húmedo montano (MAE SUIA, 2012).

Se colectaron 32 muestras de heces fecales a lo largo de los senderos de las zonas de Reventazón, Pondoña, Caldera o Cráter, El Chivo, Lulumbamba, Moraspungo, Mauca Quito, y El Placer (Figura 1). La zona de mayor recolección fue Pondoña (12/32) con un 39\% del total de muestras (Figura 2). Este porcentaje estuvo constituido por heces encontradas en los alrededores del cerro Pondoña, cerca de la comunidad San Isidro. La Reventazón ocupó el segundo lugar con un 26\%, mientras que en El Chivo se encontró un 13\%, seguido por en el Cráter con 10\%. En las zonas de Moraspungo, El Placer, Mauca Quito y Lulumbamba, se encontró la menor cantidad de muestras con un $3 \%$. 
Análisis morfológico, dietario y molecular de heces recolectadas en la Reserva Geobotánica Pululahua para la identificación del lobo de páramo.

Estefany Jarrín-Porras, Dayana Sandoval-Morejón, Erika Llumiquinga, Cristina Paredes-Machado, Mayra Heredia, María Augusta Chávez-Larrea, María Claudia Segovia-Salcedo - VINCULOS-ESPE (2020) VOL.5, No.3: 33 - 49

Figura 1: Coordenadas geográficas de los puntos de recolección de las muestras de heces fecales del lobo de páramo (Lycalopex culpaeus) en la Reserva Geobotánica Pululahua.

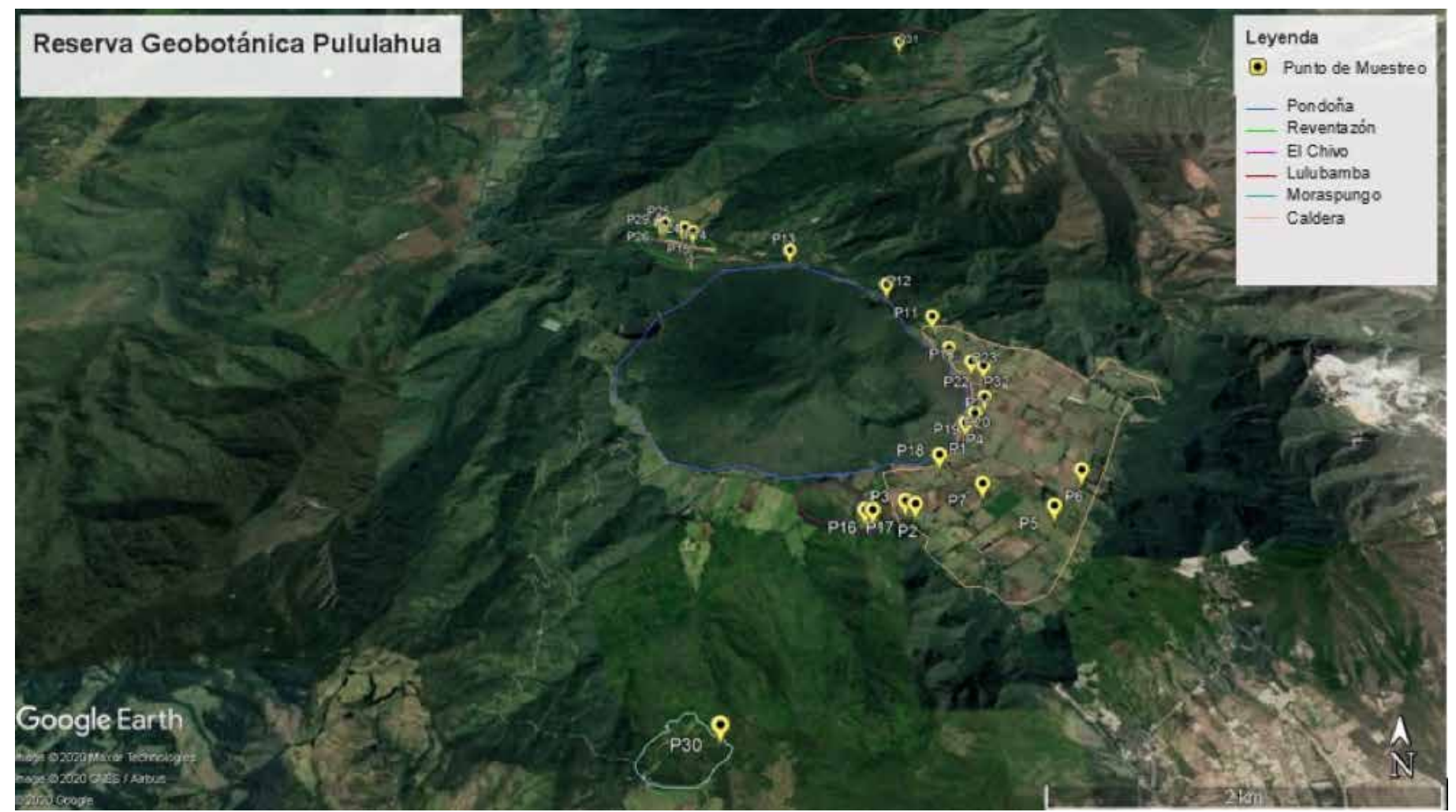

\section{Análisis morfológico de las muestras recolectadas} U. Siguiendo características generales de forma (constricciones y terminaban en punta, el 40,62\% no tenía punta, y el 9,38\% restante no fue posible la diferenciación dado que las muestras no se conservaron íntegras. El 56,25\% de las heces tienen forma de cuerda, 6,25\%

restante fue difícil su descripción por estar desintegradas. Para el caso de la presencia o ausencia de constricciones se identificó que el $12,5 \%$ de las de muestras fecales presentaban constricciones; $12,5 \%$ no las tenían y el $75 \%$ restante no se pudo diferenciar a qué grupo pertenecían. Cabe mencionar que todas las muestras fueron encontradas al aire libre y en senderos. 
Figura 2: Frecuencia de colección de las muestras fecales encontrados en la Reserva Geobotánica Pululahua.

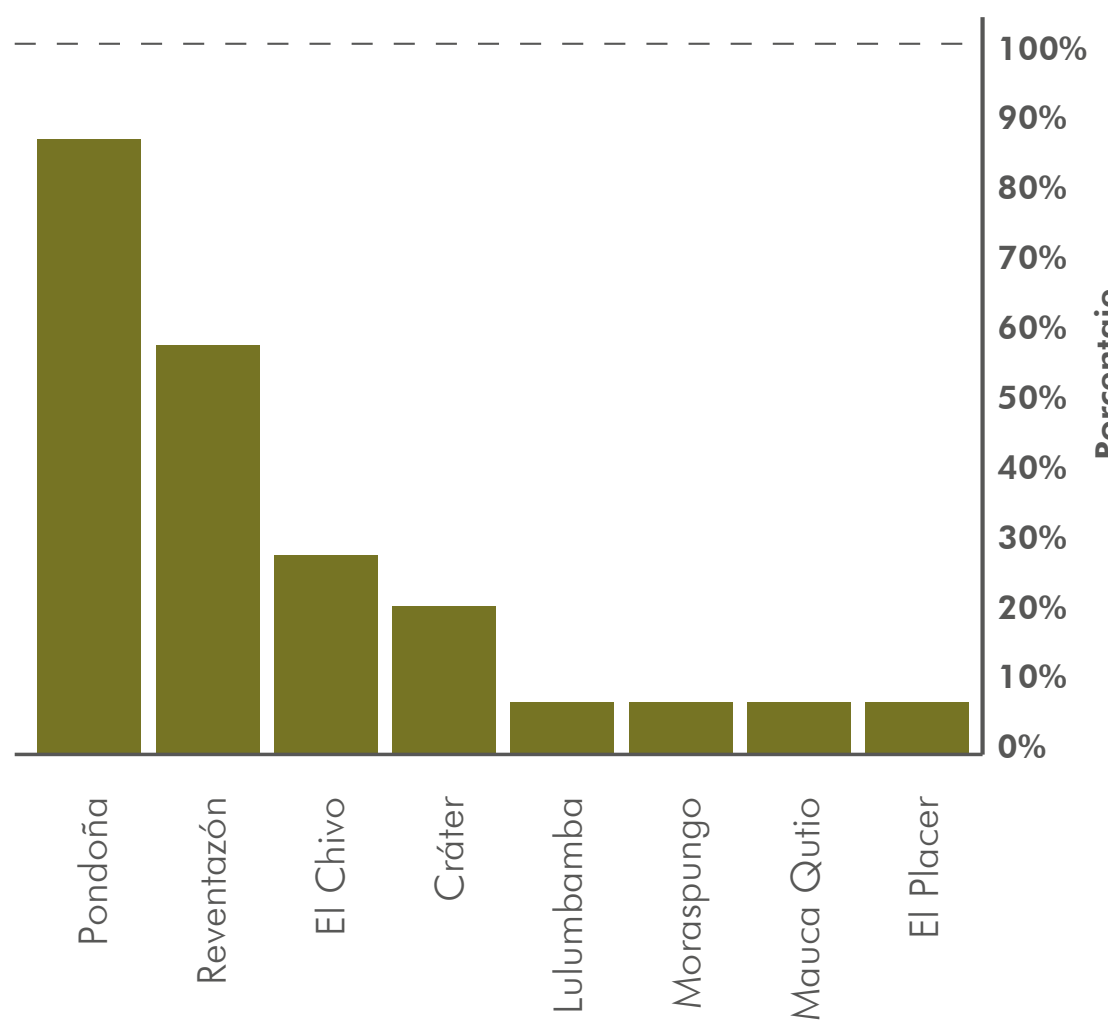

\section{Análisis de la dieta del lobo de páramo}

De las muestras fecales se recuperaron principalmente huesos, plumas, uñas, pelo, partes de invertebrados y plantas (Figura 3). Se identificó restos de animales como mamíferos (18\%), aves (7\%), e invertebrados (10\%). También se hallaron restos de plantas, los cuales representaron un $26 \%$ del total de alimentos consumidos por el lobo de páramo (L. culpaeus) que habita la Reserva Geobotánica Pululahua (Figura 4).
Figura 3. Restos de alimentos identificados en las heces recolectadas dentro de la Reserva Geobotánica Pululahua.

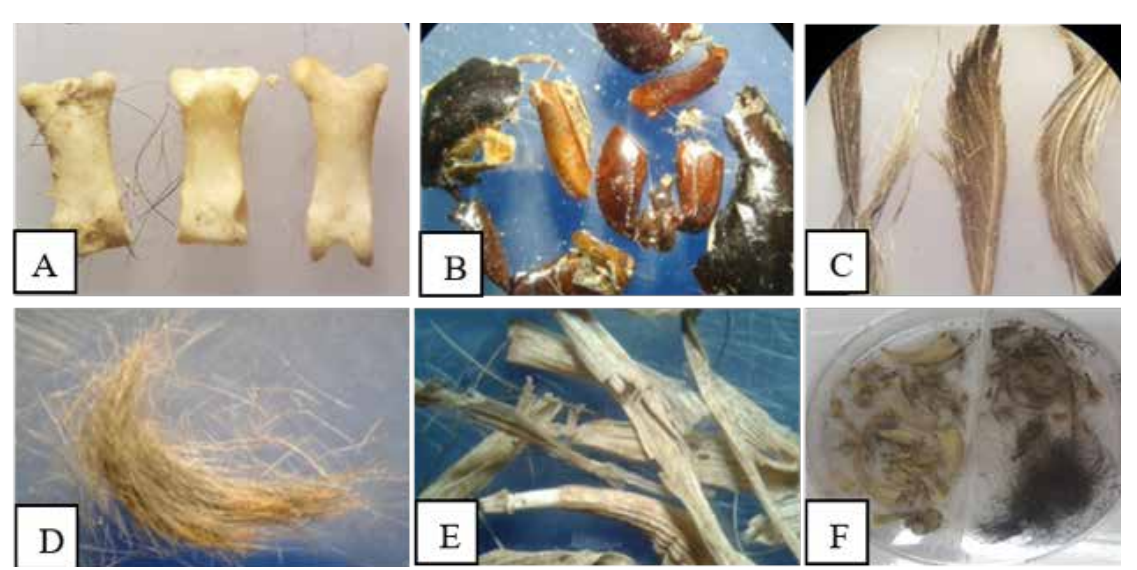

A) Restos de huesos, B) restos de escarabajos, C) restos de plumas, D) restos de pelo, E) restos de plantas, F) restos de animales encontrados en una de las muestras.

Figura 4. Frecuencia de alimentos identificados como consumo del lobo de páramo (L. culpaeus) de la Reserva Geobotánica Pululahua.

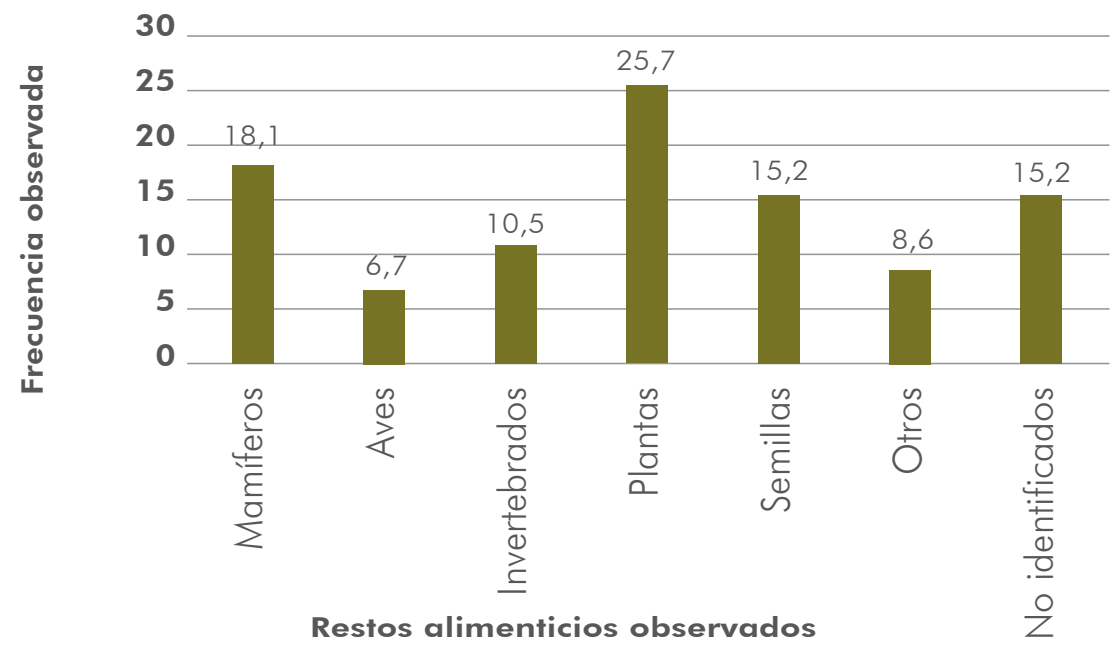


Análisis morfológico, dietario y molecular de heces recolectadas en la Reserva Geobotánica Pululahua para la identificación del lobo de páramo.

Estefany Jarrín-Porras, Dayana Sandoval-Morejón, Erika Llumiquinga, Cristina Paredes-Machado, Mayra Heredia, María Augusta Chávez-Larrea, María Claudia Segovia-Salcedo - VÍNCULOS-ESPE (2020) VOL.5, No.3: 33 - 49

Entre los restos de huesos se encontraron hileras de dientes y mandíbulas, donde se identificaron especies de ratones silvestres como Microryzomys minutus, Rhipidomys sp. (cf. latimanus), Reithrodontomys soderstromi millei, Oligoryzomys sp. y Reithrodontomys soderstromi (Figura 5A, 5B, 5C). La mandíbula de Rhipidomys sp., coincidió con la especie Rhipidomys latimanus, conocido comúnmente como rata trepadora de pies anchos. Las uñas y dientes recuperados de los restos fecales correspondían a zorrillo, posiblemente de la especie Conepatus semistriatus, (Figura 5D), mientras que las muestras de pelo halladas coinciden con el conejo de páramo Sylvilagus brasiliensis (Figura 5E).

Figura 5. Restos de animales recuperados de heces de lobo de páramo en la RGP.
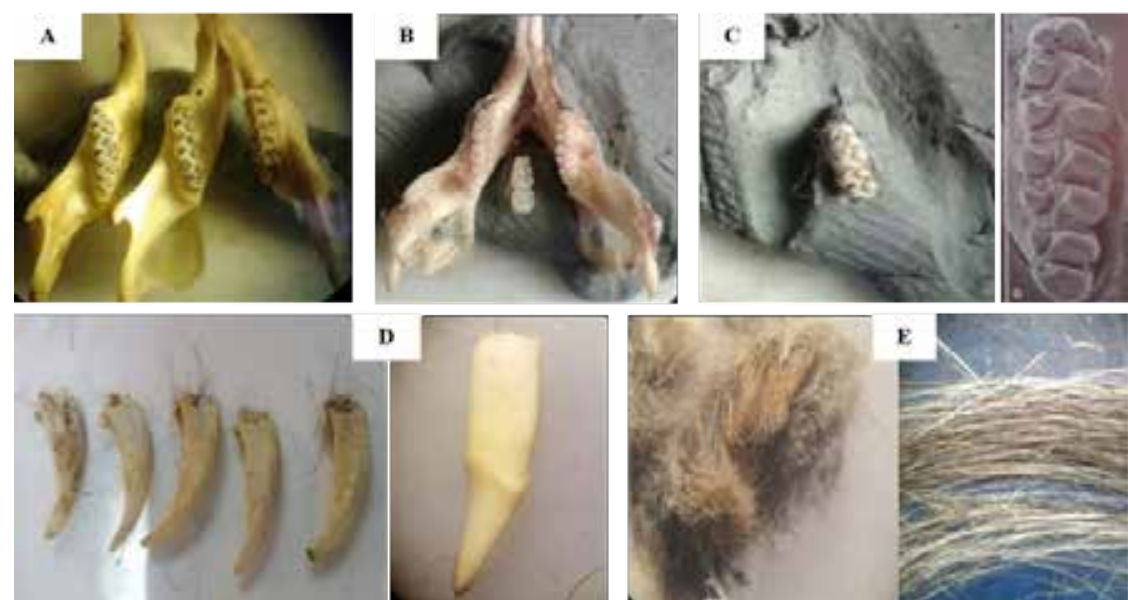

い) sp. D) Garras y diente de zorrillo (Conepatus semistriatus). E) Pelo de conejo (Sylvilagus brasiliensis).
Dentro del grupo de las aves se identificó restos de plumas y huesos pertenecientes al mirlo (Turdus merula, Figura 6A) y gallina (Gallus gallus, Figura 6B). Se encontró restos de exoesqueleto de escarabajos del género Platycoelia (Figura 6C) y otros insectos no identificados. Por otra parte, las plantas observadas (Figura 3D) correspondían a especies silvestres presentes en la zona, tales como poa (Poa annua), kikuyo (Pennisetum clandestinum) y otras de la familia Poceae. Adicionalmente, se encontraron restos de semillas, gusanos, plástico, papel y otros organismos (Tabla 2).

Figura 6. Restos de animales recuperados de heces de lobo de páramo en la RGP

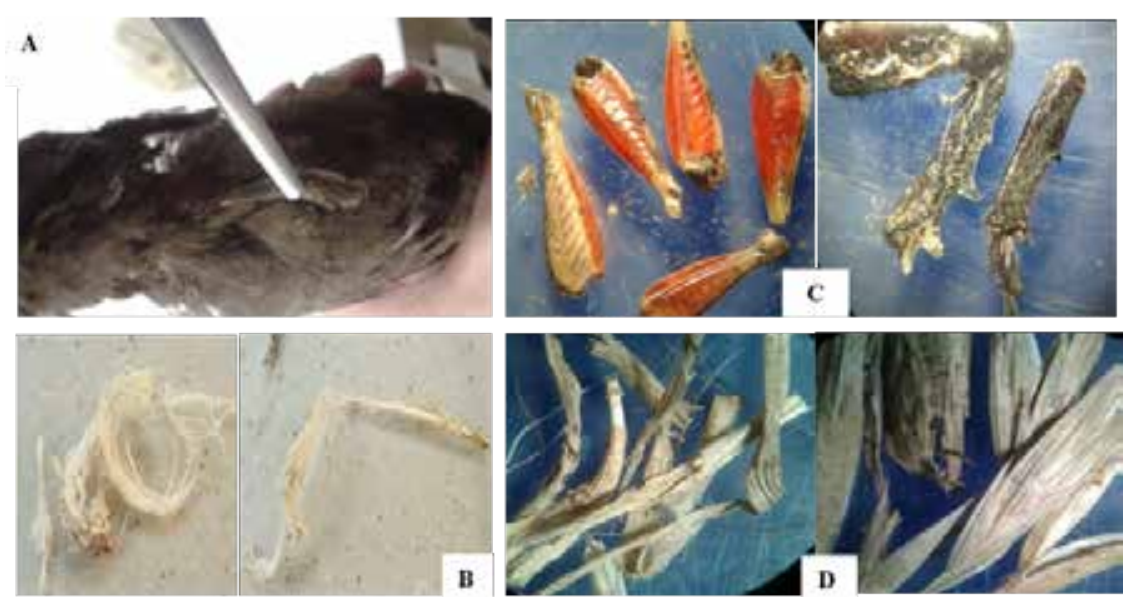

A) Comparación de plumas de la muestra (arriba) y colección (abajo) de mirlo (Turdus merula), B) Raquis y plumas de gallina (Gallus gallus), C) Extremidades de catzos del género Platycoelia, D) Kikuyo (Pennisetum clandestinum) y poa (Poa annua), izquierda y derecha, respectivamente. 
Tabla 2: Especies de animales identificadas en la dieta del lobo de páramo (Lycalopex culpaeus).

\begin{tabular}{lll} 
Categoría & Nombre común & Nombre científico \\
& Ratón & Microryzomys minutus \\
& Zorrillo & Conepatus semistriatus \\
& Ratón & Rhipidomys sp. (cf. latimanus) \\
Mamíferos & Ratón & Reithrodontomys soderstromi millei \\
& Ratón & Reithrodontomys soderstromi \\
& Ratón & Oligoryzomys sp. \\
& Conejo de páramo & Sylvilagus brasiliensis \\
\hline \multirow{3}{*}{ Aves } & Gallina & Gallus \\
& Mirlo & Turdus merula \\
\hline Invertebrados & Catzo & Platycoelia sp. \\
\hline \multirow{2}{*}{ Plantas } & Poa & Poa annua \\
& Kikuyo & Pennisetum clandestinum \\
\hline \multirow{3}{*}{ Otros } & Astillas de huesos, & \\
& plástico, madera, & \\
& piedras, gusanos, \\
& otros. &
\end{tabular}

\section{Análisis molecular de las muestras}

Se logró extraer satisfactoriamente el ADN de cuatro muestras con un rendimiento promedio de $1.78 \mathrm{~nm}$ (Tabla 3). Las bandas de ADN se observaron íntegras, pero con diferencia en su concentración en las muestras analizadas (Figura 7) que, de manera general, al comparar con las bandas de ADN de la muestra de zoológico (control positivo), se observó una menor cantidad de ADN obtenido. La muestra LC001B y LC0019B no presentaron banda de ADN después del revelado.
Figura 7. Resultados electroforesis en gel de agarosa al $0,8 \%$ de $A D N$ de heces de perro y lobo extraído por el método 2CTAB/CAI.

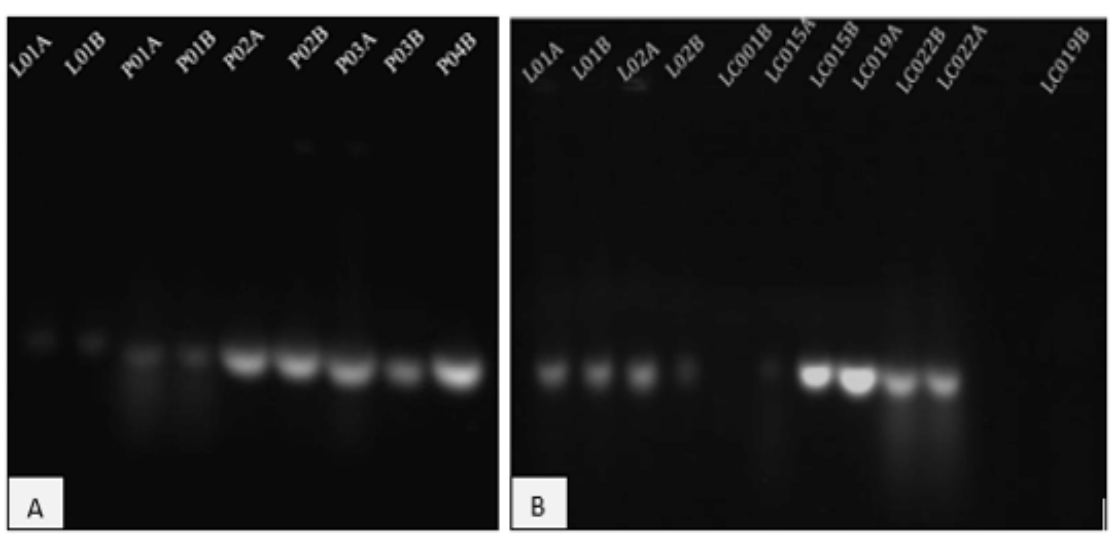

A) Primera electroforesis, donde LO1A y LO1B corresponden a muestras de heces frescas de lobo de zoológico, mientras que P01A, P01B, OP2A, P02B, P03A, P03B y P04B provienen de heces semi-secas de perro. B) Segunda electroforesis, donde L01A, L01B, L02A y L02B pertenecen a muestras de heces frescas de lobo de zoológico y donde LC001B, LC015A, LC015A, LC019A, LC022B, LC022A y LCO19B pertenecen a heces de lobo de la RGP.

Tabla 3: Rendimiento de la extracción de ADN de heces de Lobo de la RGP, mediante el método 2CTAB/CAl.

\begin{tabular}{ccccc} 
& \multicolumn{3}{c}{$\mathbf{A}$} & $\mathbf{B}$ \\
\cline { 2 - 5 } Muestra & $\begin{array}{c}\text { ADN } \\
{[\mathbf{n g} / \boldsymbol{\mu L}]}\end{array}$ & $\begin{array}{c}\mathbf{A} \\
\mathbf{2 6 0 / 2 8 0} \\
\mathbf{n m}\end{array}$ & $\begin{array}{c}\text { ADN } \\
{[\mathbf{n g} / \boldsymbol{\mu L}]}\end{array}$ & $\begin{array}{c}\mathbf{A} \\
\mathbf{2 6 0 / 2 8 0} \\
\mathbf{n m}\end{array}$ \\
LC001 & 37,3 & 1,55 & 31,1 & 1,5 \\
LC015 & 195,5 & 1,7 & 432,7 & 1,96 \\
LC019 & 410,0 & 2,13 & 194,4 & 1,85 \\
LC022 & 718,5 & 1,75 & 828,3 & 1,81 \\
\hline A 260/280: Relación de la absorbancia 260/280 nm. ADN: Ácido \\
desoxirribonucleico.
\end{tabular}


Las 4 muestras fueron empleadas para el análisis por PCR para la identificación de Lycalopex culpaeus, en conjunto con el control positivo y el control negativo. El fragmento que se esperó obtener fue de aproximadamente $200 \mathrm{pb}$ correspondiente al citocromo b (Cytb). De las 4 muestras, se logró amplificar satisfactoriamente el control positivo (Figura 8) con una intensidad débil de banda.

Figura 8. Amplificación del fragmento Cytb a partir del ADN de lobo de páramo (Lycalopex culpaeus) obtenidas del zoológico de Cuenca.

Fragmentos observados en gel de agarosa al $2 \%$.

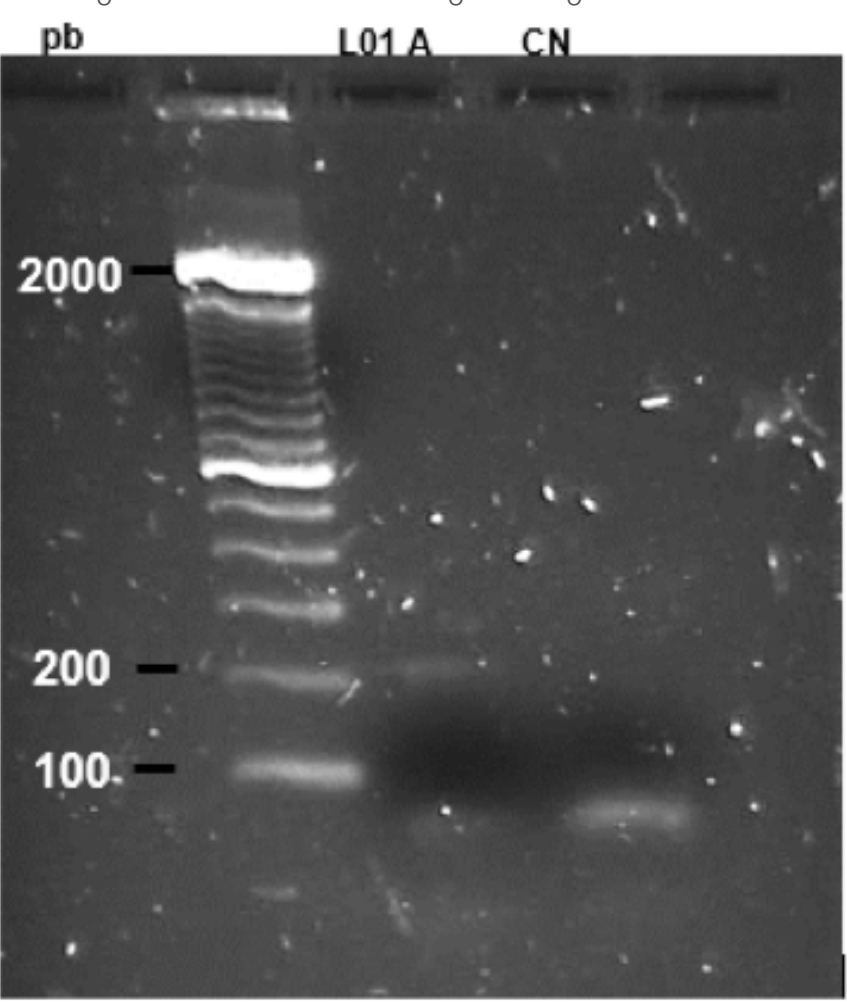

\section{DISCUSIÓN}

La Reserva Geobotánica Pululahua es un área protegida que presenta la particularidad de no solo albergar dentro de su territorio a fauna silvestre sino también a una comunidad que reside dentro de la caldera y que ocupa alrededor de 200 hectáreas de tierras agrícolas. La cercanía de un asentamiento humano a las especies silvestres ha demostrado que ocasiona cambios en los comportamientos de los animales, influyendo por ejemplo en sus patrones reproductivos (Arroyave Maya et al., 2006) y en su alimentación (Grandin \& Deesing, 2013), llegando incluso a depender del ser humano para su sobrevivencia.

En Ecuador, el lobo de páramo habita en la región Sierra distribuyéndose en los bosques templados y páramo de todo el país, y puede ocupar zonas con climas húmedos o secos (Urgilés-Verdugo \& Gallo V., 2018). Dentro de la Reserva, se encontró que el lobo de páramo está ampliamente distribuido y que ocupa hábitats que van desde el bosque húmedo hasta el bosque seco (MAE SUIA, 2012), lo que se evidenció por la frecuencia en la recolección de las muestras de heces en las diferentes zonas visitadas. La mayor cantidad de muestras de heces recolectadas fue en los senderos de la zona del Pondoña, las cuales se encontraban cerca de la comunidad San Isidro. La cercana convivencia entre el lobo de páramo y asentamientos humanos genera cambios en su comportamiento ya que tiende a agruparse en lugares donde se encuentre basura humana (Jiménez \& Novaro, 2004). En el caso de la Reserva, la comunidad San Isidro hace responsable al lobo de páramo por la desaparición de las gallinas criadas por la comunidad.

La identificación de heces es una herramienta que permite diferenciar a qué tipo de animal pertenece la muestra al momento de la colecta en campo (Halfpenny, 1986), La diferenciación entre zorros y gatos se debe prestar especial atención en la forma y lugar donde se recogen 
(Gibbons, 2003; Palacios, 2007). Ciertas características ayudan a distinguir heces de especies de animales cuya forma depende de la alimentación de cada animal (Chame, 2003), por ejemplo, los herbívoros depositan heces de mayor volumen y forma redonda, mientras que carnívoros, como L. culpaeus, presentan heces en forma de cuerda (cilindro alargado), con una terminación afilada, en punta (Lastra, 2001) o forma de colas (Halfpenny, 1986). Una manera de diferenciar entre gatos andinos y zorros o lobos de páramo es por las constricciones en sus heces, donde los primeros poseen segmentaciones cortas a manera de rosario, mientras que en los segundos las heces presentan constricciones separadas (Palacios, 2007).

Las muestras analizadas presentaban características de terminación en punta y constricciones separadas, y en cuanto a aquellas muestras donde no se logró distinguir, se consideró como referencia la zona y el lugar (al aire libre) para determinar que pertenecían a la especie en estudio.

Del análisis de la dieta se logró determinar que, en su mayoría, consume mamíferos pequeños como conejos y roedores presentes en la zona que habita, similar a lo reportado en otros estudios (BeltránOrtiz, Cadena-Ortíz, \& Brito, 2017), junto con insectos, aves y plantas (Guzmán-Sandoval et al., 2007; Zúñiga \& Fuenzalida, 2016).

Se encontró coincidencias de Rhipidomys latimanus entre los restos recuperados, un roedor comúnmente conocido como rata trepadora de pies anchos (A. Vallejo \& Boada, 2017), cuya distribución geográfica se ha reportado en bosques andinos de elevaciones medias (450-2 $200 \mathrm{~m}$ ) del centro y este de Colombia, centro-norte de Perú, bosques fríos (3000 m) en Colombia, zonas elevadas del este de Venezuela (1 600 m-2 422 m) y al este de Panamá (Eisenberg \& Redford Kent H, 1999; Gómez-Laverde, Tirira, \& Delgado, 2016; A. Vallejo \& Boada, 2017; D. Wilson \& Reeder, 2005). En Ecuador se ha reportado en zonas centro (D. Wilson \& Reeder, 2005) y sur
(Eisenberg \& Redford Kent H, 1999) del país, habita comúnmente en zonas costeras, bosques húmedos, secos, templados, tropicales y subtropicales (A. Vallejo \& Boada, 2017), es poco común en Ecuador y su ubicación en la elevación más alta reportada es de $2400 \mathrm{~m}$ según la Lista Roja de la UICN de especies amenazadas (GómezLaverde et al., 2016), coincidiendo con la elevación promedio (2 480 m) que comprenden los lugares donde se recolectaron las muestras en la Reserva Geobotánica Pululahua, siendo otro avistamiento de este animal en la parte centro-norte de Ecuador.

Se halló restos de Conepatus semistriatus, un animal carnívoro que expulsa fluidos de un olor desagradable por sus glándulas anales como defensa contra depredadores (Walker, 2004). Ya se ha reportado este tipo de presas entre los restos alimenticios de heces de lobo de páramo (Guntiñas, Lozano, Cisneros, Narváez, \& Armijos, 2017), incluso se ha reportado restos de Puma concolor (Guntiñas et al., 2017), por lo que surge especulaciones de que este tipo de animal (zorrillo) en vez de ser cazado, es consumido como carroña, concordando con Trujillo, F. \& Trujillo (2007) quien afirma que el lobo de páramo en un animal oportunista que selecciona presas fáciles (Trujillo \& Trujillo, 2007).

De las 32 muestras analizadas, sólo en dos se encontraron plumas y huesos de G. gallus. La comunidad asentada dentro del cráter de la reserva y que posee aves de corral, apuntan al lobo de páramo como el principal responsable de las desapariciones de sus animales. Este conflicto hombre-fauna que se establece en la reserva es común, sin embargo, en este estudio se establece que el lobo de páramo no es el depredador principal de estas aves domésticas.

El problema en la amplificación de los fragmentos de citocromo b de las muestras analizadas se puede explicar debido a problemas en el protocolo de extracción de ADN, la pureza de la muestra y en la conservación de las muestras previo el análisis. 
Análisis morfológico, dietario y molecular de heces recolectadas en la Reserva Geobotánica Pululahua para la identificación del lobo de páramo.

Estefany Jarrín-Porras, Dayana Sandoval-Morejón, Erika Llumiquinga, Cristina Paredes-Machado, Mayra Heredia, María Augusta Chávez-Larrea, María Claudia Segovia-Salcedo - VÍNCULOS-ESPE (2020) VOL.5, No.3: 33 - 49

La diferencia de concentración de ADN que se obtuvo entre las muestras de perro (control negativo) y lobo de páramo de zoológico (control positivo) se debe principalmente a la dieta. Los lobos de páramo dentro del zoológico se alimentan mayoritariamente de proteínas y carbohidratos, mientras que los perros tienen una alimentación balanceada de todos los nutrientes. Según Quinga et al., (2012), la presencia de una mayor descomposición de elementos orgánicos en las muestras de zoológico puede interferir en la extracción y posterior amplificación de ADN.

En la muestra LC001B recolectada en la Reserva no se observó la presencia de banda debido a la edad y a la abundante presencia de pelo en la muestra de heces, que impidieron recuperar células epiteliales del lobo para la obtención de ADN. En el caso de la muestra LC019A, a pesar de haberse extraído paralelamente con la muestra LCO19B, no se presentó ADN, lo que indica un error del operador al colocar la muestra en el pocillo (Kuhn, 2011).

En cuanto a la "pureza" de las muestras de ADN extraídas, la absorbancia 260/280 se considera un parámetro para medirla, siendo aceptable cuando sus valores son de aproximadamente 1.8. Si este valor es apreciablemente inferior, podría indicar la presencia de proteínas, fenol u otros contaminantes que absorben fuertemente longitudes de onda de $280 \mathrm{~nm}$ (Matlock, 2015). Debido a que se obtuvo una relación A 260/280 promedio de 1.78 en las muestras extraídas a partir de las heces recolectadas en la Reserva, las muestras de ADN posiblemente presentaron algún contaminante que impidió la amplificación por PCR. Cuando el ADN tiene menor cantidad de contaminantes, hay menos probabilidad de incidencia de inhibidores de PCR, y puede amplificarse mejor (Quinga, Chávez-Larrea, \& Proaño-Pérez, 2012). La presencia de inhibidores es la principal causa de que una PCR no funcione, aun cuando hay un suficiente número de copias de ADN presentes (Alaeddini, 2012).
A pesar de la falta de amplificación del fragmento de 200 pb esperado, la presencia del fragmento del control positivo indica que tanto el protocolo de PCR, así como de los primers empleados, funcionaron correctamente, aunque cabe resaltar que la banda del fragmento Cytb que presentó el control positivo tenía una intensidad débil, es decir, una menor concentración de la esperada. Existen diversos factores que pudieron afectar la reacción entre la que se encuentra la calidad de ADN.

Adicionalmente, la muestra de zoológico presentó una pureza promedio de 1.63, por lo que pudo encontrarse contaminantes que inhibieron parte de la reacción. El problema pudo también estar relacionado con la degradación del ADN durante el periodo de preparación del master mix para la PCR. El ADN es una molécula cuyas propiedades fisicoquímicas pueden ser modificadas por cambios de temperatura o contaminantes externos (Dorado, 2015). Las muestras de ADN extraídas fueron almacenadas a $-80{ }^{\circ} \mathrm{C}$, pero al momento de la preparación, al $A D N$ se lo mantuvo a temperatura ambiente, además de que pudo existir una contaminación por error de operación. Estos errores pueden resolverse al almacenar la muestra de ADN a $-80{ }^{\circ} \mathrm{C}$ hasta completar la preparación del master mix o se puede contener al ADN en hielo durante la preparación. De igual forma, se puede establecer un protocolo estricto de desinfección del área de preparación de la muestra para disminuir los errores del operador.

Dentro de la $\mathrm{PCR}$, la cantidad de $\mathrm{MgCl}$, polimerasa y primers debe ser la adecuada para evitar cualquier inhibición por exceso de reactivos (Dorado, 2015). En el caso de la PCR de identificación, las cantidades de los reactivos fueron calculadas a partir del protocolo de Quinga (2012). De igual forma, la ausencia o una menor concentración de primers pudo evitar que la reacción continúe, generando una menor cantidad de producto de PCR con respecto al esperado. Es por ello que, para futuros ensayos, es necesario reestandarizar el protocolo de extracción de ADN y el de PCR para la identificación del lobo de páramo. 


\section{CONCLUSIONES}

Las zonas del Pondoña y La Reventazón representaron los lugares de mayor ocurrencia de muestras recolectadas. Con base en el análisis morfológico se logró identificar que las muestras recolectadas pertenecían a la especie en estudio.

Los alimentos más consumidos por el lobo de páramo fueron plantas y mamíferos pequeños como conejos y roedores de la zona.

En cuanto a la depredación de gallinas pertenecientes a la comunidad San Isidro por parte del lobo de páramo, se determinó que estas aves domésticas sí forman parte de su dieta debido a su fácil acceso, sin embargo, no representan el alimento de preferencia.

También se consideró que se alimenta de carroña, puesto que se hallaron restos de zorrillo y mirlo, animales de difícil cacería por sus métodos de defensa y agilidad de vuelo, respectivamente. El lobo de páramo es un animal oportunista, que presenta una dieta variada, dependiendo de la disponibilidad del alimento en la zona.

Mediante los análisis moleculares no se logró confirmar la especie L. culpaeus a partir de las muestras de heces recolectadas en la Reserva debido a factores como inhibidores de PCR, por ello no fue posible determinar el comportamiento animal de cada una de las muestras analizadas al empatarlas con las coordenadas de los lugares de recolección.

Estas técnicas de análisis aplicadas en este estudio demuestran ser una gran herramienta para la conservación de especies silvestres, como el lobo de páramo, que comparten hábitat con asentamientos humanos.

Agradecimientos: Los autores agradecen a todos los miembros de la Reserva Geobotánica Pululahua.
También agradecen al mastozoólogo Pablo Moreno y a la ornitóloga Edith Montalvo, miembros del Instituto de Ciencias Biológicas de la Escuela Politécnica Nacional y al Dr. Armando Reyna de la Universidad de las Fuerzas Armadas ESPE por sus colaboraciones.

Este trabajo fue apoyado por la Universidad de las Fuerzas Armadas ESPE.

Financiamiento: Este trabajo fue financiado por los autores y el Laboratorio de Biotecnología Animal de la Universidad de las Fuerzas Armadas ESPE.

Cumplimiento de normas éticas: CBM/COBI-001 (07-04-2006).

Conflicto de intereses: los autores declaran que no tienen ningún conflicto de intereses.

Descargo de responsabilidad: Las opiniones expresadas en este artículo son las de los autores y no reflejan necesariamente la política oficial o la posición de la Universidad de las Fuerzas Armadas ESPE.

\section{REFERENCIAS}

Alaeddini, R. (2012). Forensic implications of PCR inhibition-A review. Forensic Science International: Genetics, 6(3), 297-305. https://doi.org/10.1016/i.fsigen.2011.08.006

Arroyave Maya, M., Gómez, C., Gutiérrez, M., Múnera, D., Zapata, P., Vergara, I., Ramos, K. (2006). Impactos de las carreteras sobre la fauna silvestre y sus principales medidas de manejo. Revista EIA, (5), 45-57. http://www.scielo.org.co/pdf/eia/n5/n5a04. pdf 
Análisis morfológico, dietario y molecular de heces recolectadas en la Reserva Geobotánica Pululahua para la identificación del lobo de páramo.

Estefany Jarrín-Porras, Dayana Sandoval-Morejón, Erika Llumiquinga, Cristina Paredes-Machado, Mayra Heredia, María Augusta Chávez-Larrea, María Claudia Segovia-Salcedo - VÍNCULOS-ESPE (2020) VOL.5, No.3: 33 - 49

Beltrán-Ortiz, E. P., Cadena-Ortíz, H., \& Brito, J. (2017). Dieta del zorro de páramo Lycalopex culpaeus (Molina 1782) en un bosque seco interandino del norte de Ecuador. Mastozoología Neotropical, 24(2), 437-441. https://www.researchgate. net/publication/321277962_Dieta_del_zorro_de_paramo_ Lycalopex_culpaeus_Molina_1782_en_un_bosque_seco_ interandino_del_norte_de_Ecuador

Canevari, M., \& Vaccaro, O. (2007). Guía de mamíferos del sur de América del Sur. Buenos Aires.

Castellanos, A., Vallejo, A. F., \& Moscoso, G. (2020). Lycalopex culpaeus. https://bioweb.bio/faunaweb/mammaliaweb/ FichaEspecie/Lycalopex culpaeus

Cedeño, W. (2016). Ecuador. Ministerio del Ambiente.

Chame, M. (2003). Terrestrial Mammal Feces: A Morphometric Summary and Description. Memorias Do Instituto Oswaldo Cruz, 98(SUPPL. 1), 71-94. https://doi.org/10.1590/S007402762003000900014

Dorado, G. (2015). Amplificación de ADN mediante PCR. Córdoba: Universidad de Córdoba. http://www.uco.es/organiza/ departamentos/bioquimica-biol-mol/pdfs/44 PCR.pdf

Eisenberg, J. F., \& Redford Kent H. (1999). Mammals of the Neotropics, Volume 3: Ecuador, Perú, Bolivia, Brazil (Vol. 3). Chicago: The University of Chicago Press.

Gibbons, D. K. (2003). Mammal Tracks and Sign of the Northeast. Londres: University Press of New England. https://books.google.com.ec/books?id= ¡MGod3ildYYC\&pg =PA $133 \& l p g=P A 133 \& d q=$ Halfpenny,
$+\mathrm{A}+$ Field + Guide + to + Mammal + Tracking +in + North + America,$+1986 \&$ source $=$ bl\&ots $=3 \mathrm{Nx} \operatorname{lnOWO7r\& sig}=$ ACfU3U2zZAZCA2UlglxXHLeuqU UWOmm Q\&hl=es\&sa= X\&ved=2ahUKEwiX5 pWvl LHoAhWpTN8KHepkBUMQ6AEw

Gómez-Laverde, M., Tirira, D., \& Delgado, C. (2016). Rhipidomys latimanus. The IUCN Red List of Threatened Species 2016. https:// doi.org/10.2305/IUCN.UK.2016-3.RLTS.T19609A22374815.en

Grandin, T., \& Deesing, M. (2013). Genetics and the Behavior of Domestic Animals. Retrieved March 26, 2020, from https://www. elsevier.com/books/genetics-and-the-behavior-of-domesticanimals/grandin/978-0-12-394586-0

Guntiñas, M., Lozano, J., Cisneros, R., Narváez, C., \& Armijos, J. (2017). Feeding ecology of the culpeo in southern Ecuador: wild ungulates being the main prey. Contributions to Zoology, 86(2), 169-180. https://doi.org/10.1163/18759866-08602004

Guzmán-Sandoval, J., Sielfeld, W., \& Ferrú, M. (2007). Diet of Lycalopex culpaeus (Mammalia: Canidae) in northernmost Chile (Tarapaca Region). Gayana, 71 (1), 1-7. https://doi.org/10.4067/S071765382007000100001

Halfpenny, J. (1986). A Field Guide to Mammal Tracking in North America (2nd ed.). Oregon: Johnson Books. https://books.google. com.ec/books? id =yNNHIYOAgtsC\&printsec $=$ frontcover\&hl = es\# $\mathrm{v}=$ onepage $\& \mathrm{q} \& f=$ false

Jiménez, J., \& Novaro, A. (2004). Culpeo (Pseudalopex culpaeus). In C. Sillero-Zubiri, M. Hoffmann, \& D. W. Macdonald (Eds.), Canids: Foxes, Wolves, Jackals and Dogs. Status Survey and Conservation Action Plan (pp. 44-49). IUCN/SSC Canid Specialist Group. 
Kuhn, R. (2011). Cómo resolver los problemas encontrados durante la separación de DNA en geles de agarosa. Retrieved March 27, 2020, from http://biomodel.vah.es/an/plasmido/0/probl.htm\%0A

Lastra, J. J. (2001). Bosques Naturales de Asturias. Universidad de Oviedo. Oviedo: Universidad de Oviedo.

MAESUIA. (2012). Plan de manejo Pululahua 2. Ministerio del Ambiente. Quito.http://190.152.46.74/documents/10179/242256/26+ PLAN+DE + MANEJO + PULULAHUA + 2+Plan + Pululahua + final+editado+mayo+2011.pdf / 8fe57537-8426-48909079-928bedcf12e1\%0A

Matlock, B. (2015). Assessment of Nucleic Acid Purity. Retrieved March 27, 2020, from https://assets.thermofisher.com/TFS-Assets/ CAD/Product-Bulletins/TN52646-E-0215M-NucleicAcid.pdf

Ministerio del ambiente del Ecuador. (2010). Cuarto informe nacional para el convenio sobre la diversidad biológica. Quito.

Ministerio del ambiente y agua. (2016). Areas protegidas, estrategia para enfrentar el cambio climático. Retrieved March 20, 2020, from https://www.ambiente.gob.ec/? s $=$ Áreas + Protegidas\%2C+ + estrategia + para + enfrentar+el + cambio + climático\%0A

Noguera-Urbano, E. A., Ramírez-Chaves, H. E., \& Torres-Martínez, M. M. (2016). Análisis geográfico y conservación del zorro andino lycalopex culpaeus (Mammalia, Canidae) en Colombia. Iheringia - Serie Zoologia, 106, 1-10. https://doi.org/10.1590/1678$4766 \mathrm{e} 2016014$

Palacios, R. (2007). Manual para la identificación de carnívoros andinos. Guía de campo. Manual para la identificación de carnívoros andinos. Guía de campo (1st ed.). CórdobaArgentina: Wildlife Conservation Network.
Quinga, M., Chávez-Larrea, M., \& Proaño-Pérez, F. (2012). Estandarización de un protocolo para la extracción de ADN de muestras fecales de lobo de páramo (Lycalopex culpaeus). Escuela Politécnica del Ejército.

Trujillo, F., \& Trujillo, J. (2007). Alimentación del lobo (Lycalopex culpaeus), en el bosque protector Jerusalén, GuayllabambaEcuador. Biología, 7, 68-75.

Urgilés-Verdugo, C., \& Gallo V., F. (2018). Guía de campo mamíferos del corredor biológico tropi-andino, Ecuador (1st ed.). Quito: Instituto de Conservación y Capacitación Ambiental.

Vallejo, A., \& Boada, C. (2017). Rhipidomys latimanus. In J. Brito, M. . Camacho, V. Romero, \& A. F. Vallejo (Eds.), Mamíferos del Ecuador (2018.0). Quito: Pontificia Universidad Católica del Ecuador. https://bioweb.bio/faunaweb/mammaliaweb/ FichaEspecie/Rhipidomys latimanus\%0A

Vallejo, J. (2015). Valoración económica del servicio estético y recreativo de la Reserva Geobotánica Pululahua, período 2014. Pontificia Universidad Católica del Ecuador. http://repositorio. puce.edu.ec/bitstream/handle/22000/9265/DISERTACIÓN. pdf? sequence $=1$ \&isAllowed $=\mathrm{y} \% 0 \mathrm{~A}$

Veintimilla, N. (2015). Presencia de enfermedades parasitarias e infeccionsas en zorros andinos que habitan en los páramos de la hacienda Antisanilla. Universidad San Fransisco de Quito. http://repositorio.usfq.edu.ec/ handle/23000/4211\%0A

Walker, R. (2004). Conepatus semistriatus, striped hog-nosed skunk. Retrieved March 27, 2020, from https://animaldiversity.org/ accounts/Conepatus_semistriatus/ 
Análisis morfológico, dietario y molecular de heces recolectadas en la Reserva Geobotánica Pululahua para la identificación del lobo de páramo.

Estefany Jarrín-Porras, Dayana Sandoval-Morejón, Erika Llumiquinga, Cristina Paredes-Machado, Mayra Heredia, María Augusta Chávez-Larrea, María Claudia Segovia-Salcedo - VÍNCULOS-ESPE (2020) VOL.5, No.3: 33 - 49

Wilson, D., \& Reeder, D. (2005). Mammal species of the world: A taxonomic and geographic reference Volumen 1. (D. E. Wilson \& D. M. Reeder, Eds.) (3rd ed., Vol. 1). Baltimore: The Johns Hopkins University Press.

Zapata, S. C., Travaini, A., Delibes, M., \& Martínez-Peck, R. (2005). Studies on Neotropical Fauna and Environment Food habits and resource partitioning between grey and culpeo foxes in southeastern Argentine Patagonia. Studies on Neotropical Fauna and Environment, 97-103. https://doi. org/10.1080/01650520500129836

Zúñiga, A. H., \& Fuenzalida, V. (2016). Dieta del zorro culpeo (Lycalopex culpaeus Molina 1782) en un área protegida del sur de Chile. Mastozoología Neotropical, 23(1), 201-205. https:// www.redalyc.org/pdf/457/45746645022.pdf

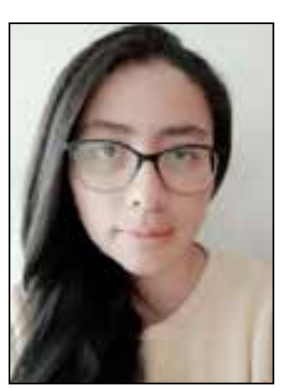

\section{ESTEFANY CAROLINA JARRÍN PORRAS}

Estudió en el Colegio Particular Paulo Freire donde obtuvo el título de bachiller en Ciencias Generales consiguiendo reconocimientos como abanderada del pabellón nacional y mejor egresada de su promoción. Es graduada de Ingeniera en Biotecnología en la Universidad de las Fuerzas Armadas - ESPE. Ha realizado pasantías en el área de salud humana y en sanidad animal. Durante su primera pasantía tuvo la oportunidad de participar en el desarrollo de un proyecto de investigación para la conservación del lobo de páramo en la Reserva Geobotánica Pululahua.

- Durante sus últimos años de estudio, Estefany colaboró con el Grupo de Investigación en Sanidad Animal y Humana - GISAH y se centró en el área de sanidad animal donde aprendió el desarrollo de técnicas de diagnóstico de enfermedades en animales.

- Actualmente trabaja en la Universidad UTE donde es la responsable de los laboratorios de Química Polifuncional, Microbiología y Morfofunción.

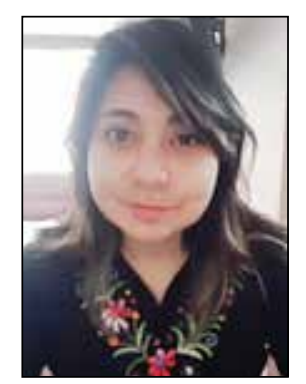

\section{DAYANA SANDOVAL}

- Ingeniera en Biotecnología graduada en la Universidad de las Fuerzas Armadas ESPE. Se desempeñó como asistente de investigación junior dentro del Grupo de Investigación en Sanidad Animal y Humana - GISAH durante su último año de carrera universitaria. Desde entonces, su trabajo está relacionado con líneas de investigación en Sanidad Animal.

Trabajó en el proyecto de sinergia realizado en colaboración entre la Universidad ESPE de Ecuador y la ACADÉMIE DE RECHERCHE ET D'ENSEIGNEMENT SUPÉRIUER- Bélgica titulado: "Mejoramiento de la Meliponicultura en Ecuador, a través de investigación científica aplicada, transferencia de tecnología y capacitación".

- Ha participado en varios proyectos dentro del grupo GISAH relacionados con el maneio y control de enfermedades como mastitis bovina, brucelosis y tripanosomiasis en Ecuador.

- Actualmente se desempeña como técnico del laboratorio de Mejoramiento Genético y Sanidad Animal dentro del Departamento de Ciencias de la Vida y la Agricultura en la Universidad de las Fuerzas Armadas ESPE. 
ERIKA MAGALY LLUMIQUINGA MARCILLO

- Nació el 04 de abril de 1993. Sus padres son Ramiro Llumiquinga y Rocio Marcillo, ambos sangolquileños. Obtuvo el bachillerato en Ciencias Generales en el Colegio Academia Militar del Valle, donde se desempeñó como comandante, brigadier mayor y fue mejor egresada de su promoción.

- Sus estudios superiores fueron en la Universidad de las Fuerzas Armadas-ESPE, durante su primera pasantía tuvo la oportunidad de estudiar los hábitos alimenticios del lobo de páramo en la reserva Geobotánica Pululahua, investigación que se ha presentado en varios congresos científicos.

- Colaboró durante tres años en el grupo de Biotecnología Industrial, desarrollando proyectos de investigación y emprendimiento relacionados a la obtención de prebióticos como suplemento nutricional para animales; logrando publicar su investigación en la revista Bionatura.

- En el 2018 obtuvo su grado de Ingeniera en Biotecnología y actualmente colabora en el Centro de Nanociencia y Nanotecnología, desarrollando proyectos enfocados a la remediación ambiente

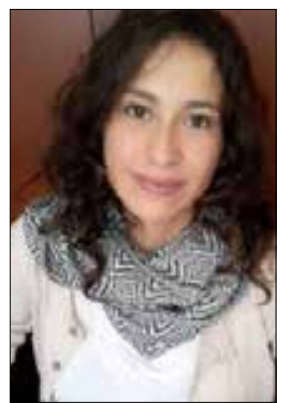

\section{CRISTINA PAREDES}

- Ingeniera en Biotecnología graduada de la Universidad de las Fuerzas Armadas - ESPE (2018). Como parte de la formación académica se involucró en un proyecto de determinación de dieta del lobo de páramo, relacionado con el área de Biología y participó en un proyecto de desarrollo de prebióticos, relacionado con el área de Biotecnología Industrial.

En el ámbito profesional, trabaió en el diagnóstico de parasitosis en el Instituto Nacional de Investigación en Salud Pública - INSPI Dr. Leopoldo Izquieta Pérez. Actualmente, se encuentra vinculada al área de investigación en seres humanos como parte del equipo que ejecuta el estudio observacional Prospective Urban and Rural Epidemiological Study - PURE, que se realiza en la Universidad UTE.

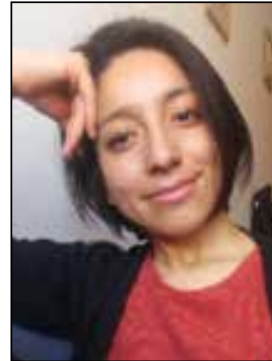

HEREDIA

- Graduada de Ingeniera en Biotecnología en la Universidad de las Fuerzas Armadas ESPE, y actualmente cursando una especialidad de Ciencia y Economía del Café en la Universidad de Trieste.

Tiene experiencia en análisis moleculares con estudios como Análisis de Expresión de genes PR en Plantas de Jigacho infectadas con Fusarium oxysporum y la parte molecular en Análisis Dietario y Molecular de Heces en la Reserva Pululahua, en dicha reserva adicionalmente realizó un análisis de calidad de aguas de fuentes naturales con indicadores ICA. Como parte de los proyectos mencionados también aplicó áreas de bioinformática para el ensamble y screening del genoma de Jigacho y subsecuente elaboración de cebadores para PCR. Enfoca sus esfuerzos en proyectos de sostenibilidad de recursos naturales del Ecuador.

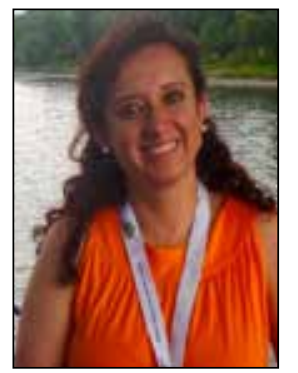

\section{CLAUDIA SEGOVIA}

Obtuvo su Licenciatura en Biología en la Pontificia Universidad Católica del Ecuador Su maestría la realizó en Ohio University en Ambiente y Biología Vegetal y su PhD en el Departamento de Botánica de University of Florida. Su investigación se centra en los ecosistemas altoandinos. Durante los últimos años ha trabajado en diferentes aspectos relacionados a bosques de los árboles de pape (Polylepis) con énfasis en su conservación y manejo. Actualmente trabaja en proyectos de código de barras genéticos en plantas andinas y conservación genética de palmas.

- Durante su carrera se ha vinculado a diferentes grupos de Mujeres en Ciencia, fue miembro activo de WISE-UF durante sus estudios de posgrado. Es miembro fundadora del grupo UF-PhDMoms que se centra en apoyar a madres estudiantes en la Universidad de Florida. En la actualidad es docente del Departamento de Ciencias de la Vida y Agricultura de la Universidad de las Fuerzas Armadas ESPE. Co-Fundadora y Coordinadora de la Red Ecuatoriana de Mujeres Científicas (REMCI). 